Egypt. Acad. J. biolog. Sci., 1 (1): 39- 48 (2009)

Email: egyptianacademic@yahoo.com

Received: 15/11/2009
E. Medical Entom. \& Parasitology

ISSN: 2090 - 0783

www.eajbs.eg.net

\title{
Spatial distribution and abundance of culicine mosquitoes in realtion to the risk of filariasis transmission in El Sharqiya Governorate, Egypt
}

\author{
Yousrya M. Abdel-Hamid; Mohamed I. Soliman and Kamilia M. Allam \\ Research Institute of Medical Entomology, The General Organization for Institutes \\ and Teaching Hospitals, Ministry of Health, Dokki, Giza, Egypt.
}

\begin{abstract}
Culicine mosquito surveys were conducted in El Sharqiya Governorate (Nov. 2007 May 2008) in some villages (cities) representing the different districts. Totally 6 species were reported: Culex (Culex) pipiens Linnaeus, $C x$. (Cx.) perexiguus Theobald, $C x$. (Cx.) antennatus (Becker), Cx. (Barraudius) pusillus Macquart, $C x$. (Cx.) sinaiticus Kirkpatrick and Ae. (Ochlerotatus) detritus (Haliday). The last two were identified as newly distributed species. Culex pipiens, the main filariasis vector was the predominant or the most common species (ca.88\% larvae and $47 \%$ adults, $\mathrm{p}<0.01$ ). For the common species, the following were examined: (1) the type and characteristics (temperature and $\mathrm{pH}$ ) of the breeding habitats and their relation to the larval density and (2) the relation of adult indoor density and indoor and outdoor temperature and RH. The AMRAD-ICT Filariasis card Test was used to detect the Wuchereria bancrofti antigen in the Finger prick blood samples. Filariasis cases $(0.4 \%, 11 /$ 2504) were detected in six out of the fifteen districts. The highest infection rate $(2.4 \%)$ was reported in the $10^{\text {th }}$ of Ramadan, a new settlement area. The cases were associated with the abundance of Cx. pipiens adults (ca. 40- 60\% of the collected adults). Digital maps showing the spatial distribution of mosquito species and filariasis cases were generated. Such maps will provide the authorities with more information about the disease risk areas that would assist in the control activities.
\end{abstract}

Keywords: Culicine mosquitoes-Spatial distribution-Abundance-Filariasis-El Sharqiya GovernorateEgypt.

\section{INTRODUCTION}

El Sharqiya is a Governorate (Fig. 1) situated in the eastern part of the Nile Delta. It is bordered from the north by El
Manzlah Lake and from the east and south by the Eastern desert, so that it represents various topographic strata including agricultural, semi desert, and desert areas.

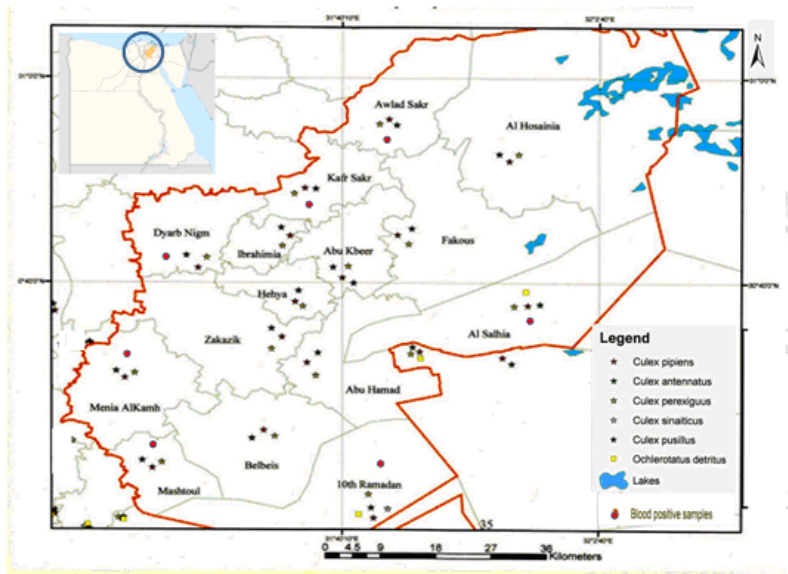

Fig. 1: Spatial distribution of culicine mosquitoes and filariasis cases in El Sharqiya Governorate

${ }^{T}$ Central Agency for Public Mobilisation and Statistics Egypt (web). THOMAS BRINKHOFF THOMAS BRINKHOFF, http://www.citypopulation.de/ 2009-02-22 
It covers about $4911 \mathrm{~km}^{2}$ with a population of 5,354,041 (2006 public census) ${ }^{1}$ and comprises of a large number of administrative centers, cities and towns.

There are fifteen districts in this Governorate. The Governorate with an agricultural area of 824,098 feddans. The most important crops are wheat, cotton, soybeans, maize, rice, several fruits (mango, lemon, citron, grabs and palm tree) and all kinds of vegetables. Its main economic resources are driven from agriculture, raising poultry and food industries. Additionally, Arab tribes of the Governorate are famous for raising best races of camels and horses.

Various water collections, extended irrigation water network and several wells are found in the Governorate. This has its impact on the occurrence and abundance of mosquitoes (Kenawy et al., 1996). Totally 10 mosquito species are known to exist in the Governorate (Kaschef et al., 1982; El-Said and Kenawy, 1983 and ElBashier et al., 2006).

Several mosquito born diseases are known and fully documented in El Sharqiya Governorate. Filariasis is a widespread disease with an incidence of 4-6\% (Shawarby et al., 1965 and Rashed, 1981) and transmitted mainly by Cx pipiens. Malaria has an old history as the only outbreak of malignant (falciparum) malaria occurred in the Nile Delta was at Inshas (Farid, 1940). Between 1982 and 1991, malaria was reported in 7 Egyptian Governorates, including El Sharqiya (Hassan et al., 2003). Today, Plasmodium vivax may be present in some parts of the Governorate and is transmitted by Anopheles pharoensis. However, currently, no malaria is recorded in Egypt (Ministry of Health, Egypt, unpublished data). The Rift Valley fever outbreak (1977-1978) occurred also in El Sharqiya (Hoogstraal et al., 1979).
The Geographic Information System (GIS) have been used widely to produce maps of disease distribution and for analyzing spatial patterns in diseases distribution. These maps have been used as tools for developing control and intervention strategies (Hassan and Onsi, 2004; Ceccato et al., 2005 and Reiter and Lapoint, 2007). Mapping the breeding habitats of the mosquito species facilitate assessment of the risk of contracting the diseases and also assist in control of the vectors (Dale et al., 1998; Thomson and Connor, 2000 and Vanwanbeke et al., 2007).

The status of mosquito abundance and their associated diseases in El Sharqiya Governorate necessitates a wide vector control program based on solid biological and ecological information of mosquito vectors. Hence, the present study was planned to provide further observations on the mosquito fauna of the Governorate and to produce health maps for the governorate showing distribution of mosquito vectors of diseases to evaluate the risk of these disease transmission.

\section{MATERIALS AND METHODS}

\section{The Study Sites:}

The work was carried out during November 2007 to May 2008 in the different districts of the Governorate. Two to three villages were selected to represent the district except the $10^{\text {th }}$ of Ramadan where the city was selected.

\section{Entomological Surveys}

Larval surveys were carried out on geographical/topographical sampling bases to determine the mosquito fauna, the species distribution, breeding habitats and factors affecting their proliferation. All water collections and sites were sampled. The temperature, and $\mathrm{pH}$ of the breeding water were recorded. Larvae were collected by netting using a round net $(17 \mathrm{~cm}$. dia.) fixed at the end of a long stick. After 
collection, larvae were kept in $70 \%$ ethyl alcohol in screw cap glass vials, labeled and transferred to the laboratory. Only $3^{\text {rd }}$ and $4^{\text {th }}$ larval instars were identified.

Adults were collected from inside houses (bed rooms and other places) by hand collection using mechanical aspirators for half an hour / room. Space spraying $(0.2 \% \%$ pyrethroid in kerosene) using total coverage (WHO, 1975) was also applied for estimation of the indoor resting densities of mosquito species per room. Samples collected were transferred to labeled boxes and taken to laboratory for counting and identification. Keys given by Kirkpatrick (1925) and Harbach (1988) were used for mosquito identification.

\section{Filariasis Survey}

In the field, the AMRAD-ICT

Filariasis card Test (ICT-Fil)

(Immunochromatographic Diagnostic Tests Company, Balgowlah, New South Wales, Australia) was used to detect the Wuchereria bancrofti antigen in the whole blood (Weil et al., 1997; Ramzy et al., 1999 and Weil and Ramzy, 2007). Finger prick blood samples were drawn onto the card (El-Setouhy et al., 2007) and the results were read visually (negative/positive) after 15 minutes. The positive cases gave two lines on the card, while negative ones gave one line only.

\section{GIS Mapping}

Digital map for Egypt was obtained from the WHO Health Mapper computer data management system for public health, showing various administration divisions of Egypt along with different shape files feature classes for lakes, rivers, roads, and elevation.

Locations (longitude and latitude) of all potential breeding sites and detected filariasis case were recorded using a global positioning system (GPS) unit using coordinate system GCS_WGS_1984 and Datum D_WGS_1984. Arc view 8, computer program was used for producing maps showing spatial distribution of each mosquito species and filariasis case in the Governorate. Satellite images for El Sharqiya Governorate were obtained through the Internet showing the land use and nature, also distribution of vegetation, agricultural areas, desert areas and populated areas of the Governorate.

\section{Statistical Analysis}

Means and Standard Deviations were calculated for larval and adult densities of the reported mosquito species. Means were compared by the one-way ANOVA and if significantly different, they were exposed to pairwise comparison by Tukey test. Multiple Regression analysis was used to examine the relation of larval density (DL) to the temperature and $\mathrm{pH}$ of the breeding water and of the adult density (DA) to the indoor (In) and outdoor (Out) temperature and Relative Humidity $(\mathrm{RH})$. The regression equations were in the form of $\mathrm{DL}=\mathrm{a}+\mathrm{b}_{1}$ Temp. $+\mathrm{b}_{2} \mathrm{pH}$ (larvae) and $\mathrm{DA}=\mathrm{a}+\mathrm{b}_{1}$ In Temp. $+\mathrm{b}_{2}$ Out Temp. $+\mathrm{b}_{3}$ In RH $+\mathrm{b}_{4}$ Out RH (adults) where $\mathrm{a}=$ constant (intercept), $\mathrm{b}_{1}-\mathrm{b}_{4}$ are the slopes (regression coefficients). The slopes were tested for deviation from 0 by t-test. The SSP (Smiths Statistical Package, version 2.75 by Gary Smith, 2004) computerized program was used for statistical analysis.

\section{RESULTS}

Composition and Relative Abundance of Mosquito Species

Six mosquito species were collected in the different districts (Table 1 and Fig. 1). These are Culex (Culex) pipiens Linnaeus, $C x$. (Cx.) perexiguus Theobald, $C x .(C x$. antennatus (Becker), $C x$. (Barraudius) pusillus Macquart, $C x$. (Cx.) sinaiticus Kirkpatrick and Aedes (Ochlerotatus) detritus (Haliday). In 67.5 collections (Survey unit; SU each of 10 net dips), a total of 29134 larvae were collected of which $C x$. pipiens was the predominant species (ca. $88 \%, 503$ larva/SU, $\mathrm{p}<0.01$ ). A total of 9232 adults were collected (space spraying: 3507 , 
$37.99 \%$ and hand collection: 5725, 62.01\%) from 599 examined rooms of which
Cx. Pipiens was the most common species (ca.47\%, 7 adult/room, $\mathrm{p}<0.01$ ).

Table 1: Species composition and relative abundance of the mosquito species in El Sharquiya Governorate

\begin{tabular}{|l|c|c|c|c|c|c|}
\hline \multirow{2}{*}{ SPECIES } & \multicolumn{3}{|c|}{ LARVAE $(\mathbf{6 7 . 5} \mathbf{S U})^{\mathbf{1}}$} & \multicolumn{3}{|c|}{ ADULTS (599 rooms) } \\
\cline { 2 - 7 } & No & $\%$ & ${\text { Mean } \pm \text { SD }^{2}}^{\mathbf{~}}$ & No & \% & Mean \pm SD $^{\mathbf{3}}$ \\
\hline Cx. pipiens & 25661 & 88.11 & $502.50 \pm 516.70 \mathrm{~A}$ & 4344 & 47.05 & $7.01 \pm 2.63 \mathrm{~A}$ \\
\hline Cx. perexiguus & 1373 & 4.71 & $42.75 \pm 108.90 \mathrm{C}$ & 2592 & 28.08 & $3.99 \pm 2.84 \mathrm{~B}$ \\
\hline Cx. antennatus & 2091 & 7.18 & $76.44 \pm 208.40 \mathrm{~B}$ & 2291 & 24.82 & $3.77 \pm 1.79 \mathrm{~B}$ \\
\hline Cx. pusillus & 5 & 0.02 & --- & 0 & 0.00 & \\
\hline Cx. sinaiticus & 0 & 0.00 & --- & 4 & 0.04 & -- \\
\hline Ae. detritus & 4 & 0.01 & --- & 1 & 0.01 & --- \\
\hline TOTAL & 29134 & & & 9232 & & \\
\hline
\end{tabular}

1. SU $=$ Survey Unit (10 net dips)

2. Mean density per district (Larvae/ SU), $\mathrm{F}_{2,35}=7.3$, , P $<0.01$, means with the different letters are significantly different, $\mathrm{P}<0.01$ (Pairwise comparisons by Tukey test).

3. Mean density per district (Adults/ room), $\mathrm{F}_{2.42}=8.2, \mathrm{P}<0.01$, means with the different letters are significantly different, $\mathrm{P}<0.01$ (Pairwise comparisons by Tukey test).

Mosquitoes were more common in Hehia (2932 Larva /SU, 30 adult / room) than in the other districts (Table 2). In all districts, $C x$ pipiens adults (3.3- 13.6 adult/room) was the most common species as compared to $C x$ antennatus (1.5- 5.4), $C x$. perexiguus (0.8-12.6), Cx. sinaiticus (0.08) or Ae. detritus (0.02) except at Ibrahimia where $C x$. antennatus was the most common species ( 8 adult/room) as compared to $C x$. pipiens (6.9) or $C x$. perexiguus (2.8). As larvae, only $C x$. pipiens was collected in Mashtoul Al Souk and Menia Al Kamh (100-116 larva/SU). In all districts, $C x$. pipiens was the most common species (33.0-1342.4 larva/SU) as compared to $C x$. antennatus (1-704), Cx. perexiguus (1.2386.0), Cx. pusillus (collected only in Abu Kbeer, 0.3 larva/SU) and Ae. detretus (collected only in Al Salhya, 1.6 larva/SU).

Table 2: Relative abundance of mosquito larvae and adults in El Sharquiya districts

\begin{tabular}{|c|c|c|c|c|c|c|c|c|c|c|}
\hline \multirow[b]{2}{*}{ DISTRICT } & \multicolumn{6}{|c|}{ SPECIES $^{1}$} & \multicolumn{2}{|c|}{ LARVAE } & \multicolumn{2}{|c|}{ ADULTS } \\
\hline & 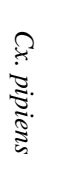 & 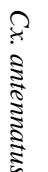 & 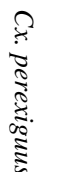 & 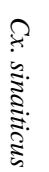 & 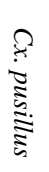 & 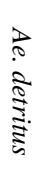 & $\begin{array}{l}Z \\
Z \\
0 \\
0 \\
\stackrel{0}{0} \\
\underset{N}{c}\end{array}$ & $\begin{array}{l}\frac{Z}{2} \\
\precsim \\
c\end{array}$ & 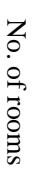 & $\begin{array}{l}\vec{o} \\
\stackrel{+}{z} \\
z \\
o \\
\overrightarrow{0} \\
o \\
\end{array}$ \\
\hline Mashtoul Al Souk & LA & $\mathrm{A}$ & A & & & & 2.0 & 116.0 & 23 & 6.2 \\
\hline Belbeis & LA & LA & LA & & & & 3.0 & 607.2 & 36 & 16.1 \\
\hline $10^{\text {th }}$ of Ramadan & LA & LA & LA & $\mathrm{A}$ & & $\bar{A}$ & 2.0 & 297.5 & 46 & 12.2 \\
\hline Menia Al Kamh & LA & $\bar{A}$ & $\mathrm{~A}$ & & & & 1.0 & 100.0 & 31 & 10.3 \\
\hline Dyarb Negm & LA & LA & LA & & & & 8.0 & 270.7 & 38 & 18.3 \\
\hline Ibrahimia & LA & LA & LA & & & & 4.0 & 758.5 & 44 & 17.7 \\
\hline Hehya & LA & LA & LA & & & & 2.0 & 2932.0 & 58 & $30.0^{\circ}$ \\
\hline Al-Zakazik & LA & A & LA & & & & 5.0 & 43.4 & 38 & 10.8 \\
\hline Abu Hammad & LA & LA & LA & & & & 4.0 & 863.0 & 43 & 12.6 \\
\hline Abu Kbeer & LA & LA & LA & & $\mathrm{L}$ & & 16.0 & 141.9 & 45 & 9.8 \\
\hline Fakous & LA & LA & $\mathrm{A}$ & & & & 2.5 & 284.8 & 34 & 21.8 \\
\hline Kafr Sakr & LA & LA & LA & & & & 5.0 & 54.4 & 46 & 13.9 \\
\hline Awlad Sakr & LA & LA & LA & & & & 7.5 & 407.5 & 42 & 14.3 \\
\hline Al Hosainia & LA & A & LA & & & & 3.0 & 668.6 & 44 & 9.3 \\
\hline Al Salhya & LA & LA & LA & & & $\mathrm{L}$ & 2.5 & 1347.4 & 31 & 18.3 \\
\hline
\end{tabular}

1. Collected as: $\mathrm{LA}=$ Larvae and Adults, $\mathrm{A}=$ Adults, $\mathrm{L}=$ Larvae

2. $\mathrm{SU}=$ Survey Unit (10 net dips)

\section{Breeding Habitats}

Mosquito larvae were found to have a variety of breeding habitats: Irrigation canals (ditches, drains, and misqas or narrow irrigation canals),
Sewage water (Cesspits and cesspools), unused sakias pits (deep wells used for irrigation) Pools, surface water, seepage water and wells. 
Effect of Water Temperature and pH on the Density of Mosquito Larvae

Multiple Regression analysis (Table 3) revealed that larval densities of the 3 common species increase as temperature increased within the range $\left(18-30^{\circ} \mathrm{C}\right)$. Larval density of $C x$. pipiens increases $(\mathrm{P}>0.05)$ and densities of $C x$. antennatus and $C x$ perexiguus decrease $(\mathrm{P}>0.05)$ as $\mathrm{pH}$ increased within the range (7.4-8.4). In general for all larvae, density increases as temperature increased $(\mathrm{P}<0.05)$ while it decreases $(\mathrm{P}>0.05)$ as $\mathrm{pH}$ increased.

Table 3: Multiple regression analysis for the effect of temperature, Relative humidity and $\mathrm{pH}$ on the density of mosquito larvae and adults

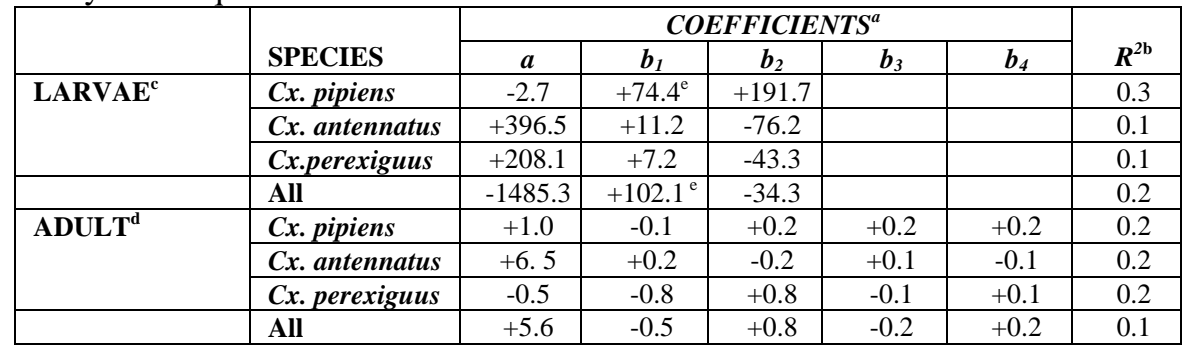

a. $\quad \mathrm{a}=$ constant (intercept), b1-b4 are the slopes (regression coefficients).

b. Coefficient of Determination.

c. Equation $\left(y=a+b_{1} x_{1}+b_{2} x_{2}\right)$ where $\mathrm{y}=$ Density, $x_{1}=$ Temperature and $x_{2}=\mathrm{pH}$

d. Equation $\left(y=a+b_{1} x_{1}+b_{2} x_{2}+b_{3} x_{3}+b_{4} x_{4}\right)$ where $\mathrm{y}=$ Density, $x_{1}=$ Indoor temperature, $x_{2}=$ Outdoor temperature, $x_{3}=$ Indoor RH and $x_{4}=$ Outdoor RH.

e. $\quad \mathrm{P}<0.05$, all others not significant, $\mathrm{P}>0.05$

Effect of Temperature and Relative Humidity on the Density of Mosquito Adults

Multiple Regression analysis (Table 3) revealed the following;

1. Cx. pipiens: Density decreases as indoor temperature (range $=16.5$ $27.9^{\circ} \mathrm{C}$ ) increased, while it increased as outdoor temperature (range $=17.5$ $29.0{ }^{\circ} \mathrm{C}$ ), indoor $\mathrm{RH}$ (range $=45.0$ 68.8 ) and outdoor RH (range $=45.7$ 68.2 ) increased $(\mathrm{P}>0.05)$.

2. Cx antennatus: Density increases as indoor temp and RH increased, while it decreases as outdoor temp. and $\mathrm{RH}$ increased $(\mathrm{P}>0.05)$.

3. Cx perexiguus: Density decreases as indoor temp. and RH increased, while it increases as outdoor temp. and $\mathrm{RH}$ increased $(\mathrm{P}>0.05)$.
4. Generally, for all adults, Density increases as outdoor temp. and $\mathrm{RH}$ increased, while it decreases as indoor temp. and $\mathrm{RH}$ increased $(\mathrm{P}>0.05)$.

\section{Parasitological Survey}

Of the total 2504 collected blood samples, $11(0.44 \%$, range $=0.51-$ $2.38 \%$ ) were positive for microfilaria of lymphatic filariasis (Table 4 and Fig. 1). Cases were reported in $10^{\text {th }}$ of Ramadan, Al Salhya, Menia Al-Kamh, Mashtoul Al Souk, Dyarb Negm, Kafr Sakr and Awlad Sakr. In addition, clinical examination showed only one elephantiasis case $(0.61 \%)$ in Kafr Sakr district. The cases were associated with the abundance of $C x$. pipiens adults (40.5-60.1\% of the collected adults) 
Table 4: Filariasis cases in El Sharquiya Governorate

\begin{tabular}{|c|c|c|c|c|c|c|}
\hline \multirow[t]{3}{*}{ District } & \multicolumn{3}{|c|}{ No. blood samples } & \multicolumn{3}{|c|}{ Mosquito adults (\%) } \\
\hline & \multirow[t]{2}{*}{ Examined } & \multicolumn{2}{|c|}{ Positive } & \multirow{2}{*}{$\begin{array}{l}\text { Cx. } \\
\text { pipiens }\end{array}$} & \multirow{2}{*}{$\begin{array}{l}\text { Cx. } \\
\text { antennatus }\end{array}$} & \multirow{2}{*}{$\begin{array}{l}\text { Cx. } \\
\text { perexiguus }\end{array}$} \\
\hline & & No. & $\%$ & & & \\
\hline Mashtoul Al Souk & 143 & 1.0 & 0.7 & 53.2 & 24.2 & 22.6 \\
\hline Belbeis & 157 & 0.0 & & 47.8 & 33.5 & 18.6 \\
\hline $10^{\text {th }}$ of Ramadan & 168 & 4.0 & 2.4 & 40.5 & 30.6 & 28.9 \\
\hline Menia Al Kamh & 142 & 1.0 & 0.7 & 55.3 & 36.9 & 7.8 \\
\hline Dyarb Negm & 195 & 1.0 & 0.5 & 50.3 & 28.4 & 21.3 \\
\hline Ibrahimia & 155 & 0.0 & & 39.0 & 45.2 & 15.8 \\
\hline Hehya & 171 & 0.0 & & 45.3 & 12.7 & 42.0 \\
\hline Al-Zakazik & 183 & 0.0 & & 51.9 & 18.5 & 29.6 \\
\hline Abu Hammad & 175 & 0.0 & & 47.6 & 23.0 & 29.4 \\
\hline Fakous & 148 & 0.0 & & 40.8 & 22.5 & 36.7 \\
\hline Abu Kbeer & 175 & 0.0 & & 49 & 20.4 & 30.6 \\
\hline Kafr Sakr* & 164 & 2.0 & 1.2 & 48.9 & 28.1 & 23.0 \\
\hline Awlad Sakr & 173 & 1.0 & 0.6 & 60.1 & 14.0 & 25.9 \\
\hline Al Hosainia & 183 & 0.0 & & 43.0 & 21.5 & 35.5 \\
\hline Al Salhya & 172 & 1.0 & 0.6 & 50.3 & 29.5 & 20.2 \\
\hline Total & 2504 & 11.0 & 0.4 & & & \\
\hline
\end{tabular}

* One clinical case was detected $(0.61 \%)$

\section{DISCUSSION}

Totally, eight culicine mosquito species were previously reported from El Sharqiya governorate (Kaschef et al., 1982; El-Said and Kenawy, 1983; Kenawy et al., 1996 \& 1998 and ElBashier et al., 2006): Culex (Culex) pipiens Linnaeus, $C x$. $(C x$.) perexiguus Theobald, $C x . \quad(C x$.$) antennatus$ (Becker), Cx. (Barraudius) pusillus Macquart, $\quad C x$. $(C x$.) poicilipes (Theobald), Aedes (Ochlerotatus) caspius (Pallas), Culiseta (Allotheobaldia) longiareolata (Macquart), Uranotaenia (Pseudoficalbia) unguiculata Edwards. During the present study, only the first four of these species were reported. In addition, two other species namely $C x$. (Cx.) sinaiticus Kirkpatrick and Ae. (Ochlerotatus) detritus (Haliday) were identified as newly distributed species.

Culex. pipiens was the predominant or the most common species (ca.88\%, larvae and $47 \%$ adults, $\mathrm{p}<0.01)$ similar to the previous observations (Gad et al., 1995; Kenawy et al., 1996 and El-Bashier et al., 2006).
This indicate the prevalence of the main filariasis vector (Harb et al., 1993) in all surveyed areas breeding mainly in drainage and irrigation canals, which are numerous in the Governorate through its fertile areas. The Governorate covers areas of fertile cultivated lands as well as newly reclaimed land (AL Salhya) and desert areas $\left(10^{\text {th }}\right.$ of Ramadan) and as appears from satellite images (Fig. 2). The areas of Cities and villages appear in the images as many small grey spots areas in the majority of green fields covering most of the districts.

Breeding habitats were found to have alkaline water $(\mathrm{pH}$ 7.4-8.4) as previously reported by Kirkpatrick (1925). In El Sharqiya rice fields, Larvae of $C x$. antennatus and $C x$. perexiguus breeding water has $\mathrm{pH}$ of 6-8 (Kenawy et al., 1998). The temperature range (18$30^{\circ} \mathrm{C}$ ) of the breeding water as observed in this study is comparable to $21-29{ }^{\circ} \mathrm{C}$ reported by Kenawy et al. (1998) in the rice fields. The difference in temp ranges for the different mosquito species could explain their breeding seasonalities. 


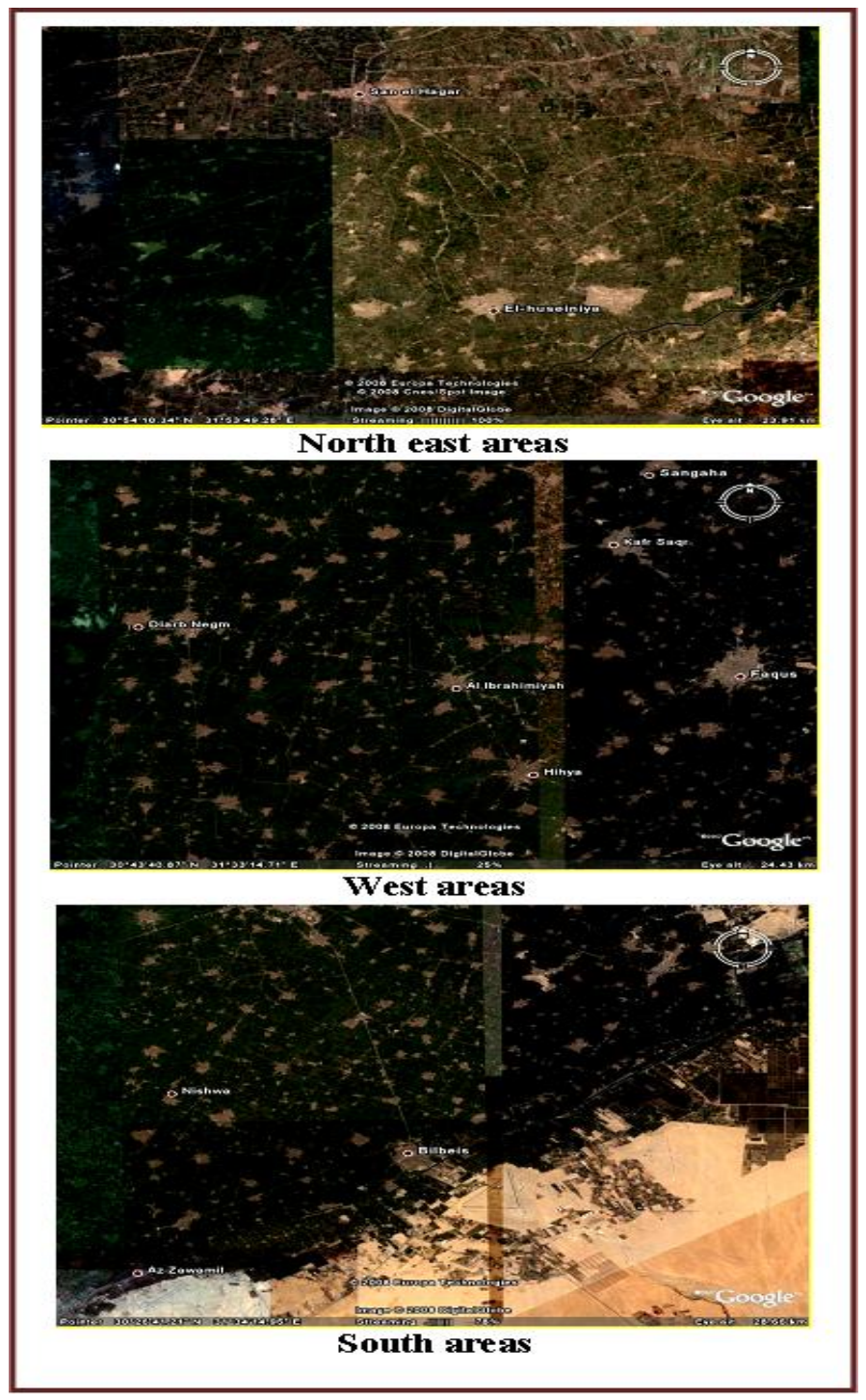

Fig. 2: Satellite images of El Sharqiya Governorate

Regression analysis revealed that larval densities of the 3 common species are directly related to water temperature. Larval density of $C x$ pipiens increases $(\mathrm{P}>0.05)$ while those of $C x$. antennatus and $C x$. perexiguus decrease $(\mathrm{P}>0.05)$ as $\mathrm{pH}$ increased $\left(\mathrm{R}^{2}=0.1-0.3\right)$. Studies on such relations in Egypt are few and included only 4 anopheline and 2 culicine species (El-Said and kenawy, 1982 and kenawy and El-Said, 1989 \&1990). In El Sharquiya, Kenawy et al. (1996) reported that densities of $C x$. antennatus and $C x$. perexiguus increased as a linear function of $\mathrm{pH}$ and temperature of the breeding water with regression coefficients (b) significantly different from $0(\mathrm{P}<0.05)$. While in $\mathrm{El}$
Sharquiya rice fields (Kenawy et al., 1998), the relation of larval densities of $C x$. antennatus and $C x$. perexiguus were positive with $\mathrm{pH}$ and negative with temperature. In the neighboring Ismailia governorate, Kenawy and El-Said (1990) reported that density of $C x$. antennatus larvae was directly proportional with water temperature and $\mathrm{pH}(\mathrm{P}>0.05)$. Several other physico-chemical factors, e.g. salinity are known to affect the survival of mosquito larvae and pupae (Sinha, 1976 and kenawy and El-Said, 1990). Indoor density of the common mosquito adults was found to increase as outdoor temperature and $\mathrm{RH}$ increased, while it decreases as indoor temperature and $\mathrm{RH}$ increased $(\mathrm{P}>0.05)$. 
No comparable results however, are available.

Data indicates that filariasis cases $(0.4 \%, 11 / 2504)$ are still to be found in this Governorate (in six out of the fifteen districts) despite the facts that our collected samples were limited and that the Governorate was covered by the Mass Drug Administration (MDA) national programme of Ministry of Health to eliminate lymphatic filariasis (Ramzy et al., 2005 and El-Setouhy et al., 2007). The highest infection rate $(2.4 \%)$ was reported in the $10^{\text {th }}$ of Ramadan, a new settlement area. The cases were associated with the abundance of $C x$. pipiens adults which gives further indication that $C x$. pipiens is the main filariasis vector in the Governorate. Moreover, Cx. pipiens was found ( $\mathrm{Gad}$ et al., 1995) to be primarily anthropophilic (forage ratio $=2.7$ ) at Abu Heif, a village in Sharqiya Governorate, the finding that support such conclusion.

The Geographic information systems have allowed researchers to visualize data distribution together with environmental parameters such as temperature and relative humidity on maps (Coetzee et al., 2000). The obtained results thus can provide a new basis for directing the control of mosquito vectors as they provide health authorities with precise maps of mosquito breeding habitats in a timely manner. Moreover, the generated map delineating risk areas could be used by project developers to either re-site the project, or invest in mosquito control activities in order to avoid health risks and ensure sustainability of their development (Hassan and Onsi, 2004).

In the present work GIS has been used to analyze the spatial distribution of vectors of diseases and disease risk in $\mathrm{El}$ Sharquiya Governorate. It was found that the breeding pattern of the vector species and the availability of its breeding sites are important variables in explaining the variability in disease transmission. Our results support findings of previous research (Bergquist, 2001) that environmental factors are important determinants of vector-born disease risk.

The distribution map of vectors and associated filariasis cases in the study areas that generated during the present investigation will provide the vector control authorities with more information that would assist in their control activities and prioritization.

\section{ACKNOWLEDGMENTS}

We are grateful to the Egyptian Ministry of Health for kindly facilitating this research and to the staff in departments of Vector Control and Endemic Diseases in El Sharqiya Governorate and the technician in Mosquito Research Department, Research Institute of Medical Entomology (RIME) for assisting with field work. Eng Mohamed Zaki (RIME) kindly assisted in mapping.

\section{REFERENCES}

Bergquist, N. R. (2001). Vector-born parasitic diseases: New trends in data collection and risk assessment. Acta tropica, 79(1):13-20.

Ceccato, P.; Connor, S. J.; Jeanne, I. and Thomson, M. C. (2005). Application of geographic information systems and remote sensing technologies for assessing and monitoring malaria risk. Parasitologia, (47)1:81-96.

Coetzee, M.; Craig ,M. and Le Sueur, D. (2000). Distribution of African malaria mosquitoes belonging to the Anopheles gambiae complex. Parasitol. Today, 16(2):74-77.

Dale, P. E.; Ritchie, S. A.; Territo, B. M.; Morris, C. D.; Muhar, A. and Kay, B. H. (1998). An overview of remote sensing and GIS for surveillance of mosquito vector habitats and risk assessment. J. Vector Ecol., 23 (1): 54-61.

El-Bashier, Z.M.; Hassan, M.I.; Mangoud, A.M.; Morsy, T.A. and Mohammad, K.A. (2006). A preliminary pilot survey (Culex pipiens), Sharkia Governorate, 
Egypt. J. Egypt. Soc. Parasitol., 36(1):81-92.

El-Said, S. and kenawy, M. (1982). Field studies on anopheline mosquito larvae in Egypt (Diptera: Culicidae), III. Influence of $\mathrm{pH}$ and salinity of the breeding water on larval density of common anopheline species. J. Egypt. Publ. Hlth. Assoc., 57: 598- 629.

El-Said, S. and Kenawy, M. (1983). Anopheline and culicine mosquito species and their abundance in Egypt. J. Egypt. Publ. Hlth. Assoc., 58(1,2):108142

El-Setouhy, M ; Abd Elaziz, K. M.; Helmy, H. ; Farid, H. A.; Kamal, H. A.; Ramzy, R.M.R.; Shannon, W. D. and Weil,' G. J. (2007). The effect of compliance on the impact of mass drug administration for elimination of lymphatic filariasis in Egypt. Am. J. Trop. Med. Hyg., 77(6): 1069-1073

Farid, M.A. (1940). Malaria infection in Anopheles sergenti in Egypt. Riv. Malariol., 19: 159-161.

Gad, A.M.; Riad, I.B. and Farid, H.A. (1995). Host-feeding patterns of Culex pipiens and $C x$. antennatus (Diptera: Culicidae) from a village in Sharqiya Governorate, Egypt. J. Med. Entomol., 32(5):573-7.

Harb, M.; Faris, R.; Gad, A.M.; Hafez, O.N.; Ramzi, R. and Buck, A.A. (1993). The resurgence of lymphatic filariasis in the Nile Delta. Bull. WHO, 71 (1):49-54.

Harbach, R.E. (1988). The mosquitoes of the subgenus Culex in the southwestern Asia and Egypt (Diptera: Culicidae). Contrib. Am. Entomol. Inst. (ann Arbor), 24 (1): $\mathrm{vi}+240 \mathrm{pp}$.

Hassan, A.N. ; Kenawy, M.A. ; Kamal, H., Abdel Sattar, A.A. and Sowilem, M.M. (2003). GIS-based prediction of malaria risk in Egypt. East Mediterr Health J., 9(4):548-58.

Hassan, A. N. and Onsi, H. M. (2004). Remote sensing as a tool for mapping mosquito breading habitats and associated health risk to assist control efforts and development plans: A case study in Wadi El Natroun, Egypt. J. Egypt. Soc. Parasitol., 34 (2): 367-82.

Hoogstraal, H.; Meegan, J.M.; Khalil, G.M. and Adham, F.K. (1979). The Rift valley fever epizootic in Egypt, 1977-1978. 2-
Ecological and entonological studies. Trans. R. Soc. Trop. Med. Hyg., 73; 624-629.

Kaschef, A.H.; Mohamed, N.H. and Rashed, S.S. (1982). Culicid species in Sharkyia Governorate. J. Egypt. Soc. Parasitol., 12(1):115-24.

Kenawy, M.A. and El-Said, S. (1989). Characterization of culicine mosquito habitats in the Nile Delta-Egypt. J. Egypt. Publ. Hlth. Assoc., 64: 211- 231.

Kenawy, M.A. and El-Said, S. (1990). Factors affecting breeding of culicine mosquitoes and their associations in the canal zone, Egypt. Proc. Int. Conf. St., Comp. Sc. Res. and Dem., 1: 215- 233.

Kenawy, M. A.; Rashed, S. S. and Teleb, S. S. (1996). Population ecology of mosquito larvae (Diptera: Culicidae) In Sharkiya Governorate, Egypt. J. Egypt. Ger. Soc. Zool., 21(E) Entomology: 121-142.

Kenawy, M.A.; Rashed, S.S. and Teleb, S.S. (1998). Characterization of rice field mosquito habitats in Sharkia Governorate, Egypt. J. Egypt. Soc. Parasitol., 28(2):449-459.

Kirkpatrick, T.W. (1925). The mosquitoes of Egypt. Egyptian Gov., Antimalaria Commission, Gov. Press, 224 pp.

Ramzy, R.M.R.; Goldman, A.S. and Kamal, H. A. (2005). Defining the cost of the Egyptian lymphatic filariasis elimination programme. Filaria J., 4: 7-29.

Ramzy, R.M.R.; Helmy, H.; El-Lethy, A.S.T.; Kandil, A.M.; Ahmed, E.S. ; Weil, G.J. and Faris, R. (1999). Field evaluation of a rapid-format kit for the diagnosis of bancroftian filariasis in Egypt. East Mediterr Health J., 5(5):880887.

Rashed, S.S. (1981). Survey of mosquito species in Sharkiya Governorate with special reference to population density of culicids transmitting filarial. M.Sc. Thesis, Fac. Sci. Zagazig Univ.

Reiter, M. E. and Lapoint, D. A. (2007). Landscape factors influencing the spatial distribution and abundance of mosquito vector Culex quinquefasciatus (Diptera: Culicidae) in a mixed residentialagricultural community in Hawaii. J. Med. Entomol., 44 ( 5): 861-68.

Shawarby, A.A.; Mahdi, A.H.; Naguib, K. and Mohamed, A. (1965). Incidence of 
filariasis in Egypt. J. Egypt. Publ. Hlth. Assoc., 40: 267- 282.

Sinha, V.P. (1976). Further observation on the physic-chemical factors of the breeding places of Culex quinquefasciatus Say = fatigans Wied. Mosq. News, 36: 358-360.

Thomson, M. C. and Connor, S. J. (2000). Environmental Information Systems for the control of Arthropoda vectors of diseases. Med. Vet. Entomol., 14 (3): $227-44$.

Vanwanbeke, S. O.; Somboon, P.; Harbach, R. E.; Isenstadt, M.; Lambin, E. F.; Walton, C. and Butlin, R. K. (2007). Landscape and land cover factors influence the presence of Aedes and Anopheles larvae. J. Med. Entomol., 44 (1): 133-44.

Weil, G.J.; Lammie, P.J. and Weiss, N. (1997). The ICT filariasis test: a rapidformat antigen test for diagnosis of bancroftian filariasis. Parasitol. Today, 13:401-404.

Weil G.J. and Ramzy, R.M. (2007). Diagnostic tools for filariasis elimination programmes. Trends Parasitol., 23:7882.

World Health Organization (1975). Manual on practical entomology in malaria. Part II. Methods and techniques.

\section{ARABIC SUMMARY}

$$
\begin{aligned}
& \text { التوزيع المكانى وغَزَرَة بعوض الكيوليسينى فيما يتعلق بأختطار نقل مرض الفيلاريا }
\end{aligned}
$$

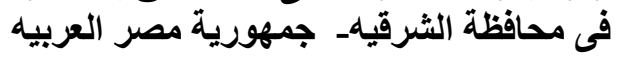

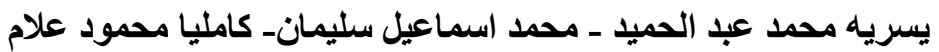

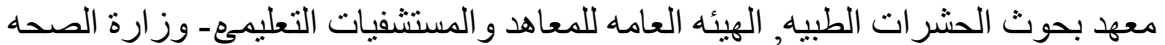

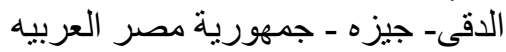

$$
\begin{aligned}
& \text { اجرى مسح لبعوض الكيوليسينى (نوفمبر } 2007 \text { - مايو 2008) فى بعض القئ القرى و المدن ممثلة }
\end{aligned}
$$

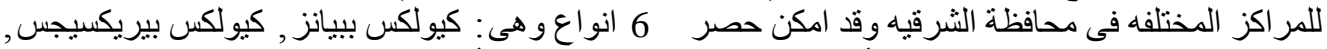

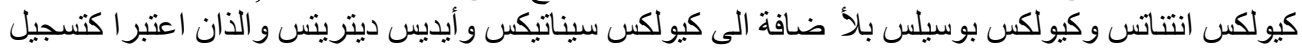

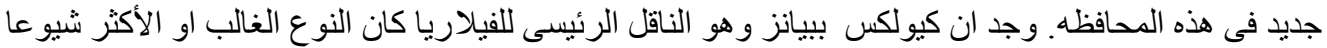

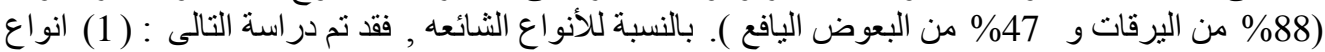

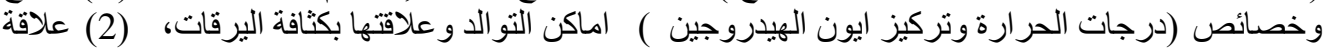

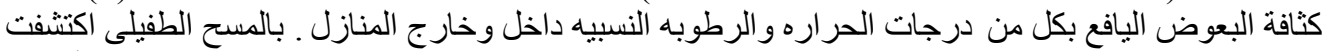

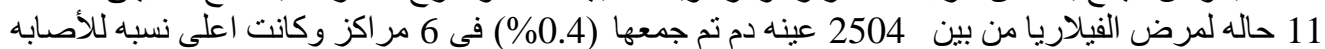

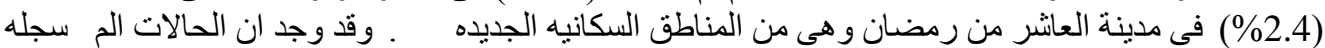

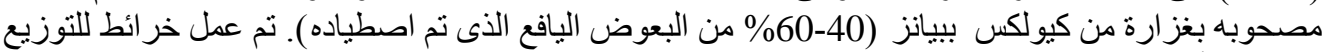

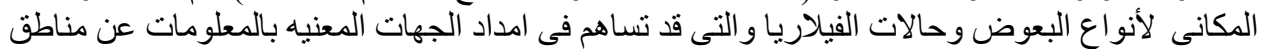

$$
\begin{aligned}
& \text { اختطار المرض و التى قد تنساعد فى اعمال المكافحه التى تقوم نها. }
\end{aligned}
$$

